\title{
A primary health care model for managing pre-eclampsia and eclampsia in low- and middle- income countries
}

Charlotte E. Warren ${ }^{* *}$, Sharif Mohammed Ismail Hossain², Salisu Ishaku ${ }^{3}$, Deborah Armbruster ${ }^{4}$ and Emily Hillman ${ }^{4}$

\begin{abstract}
Background: Hypertensive disorders in pregnancy, specifically pre-eclampsia and eclampsia (PE/E), are the second biggest killer of pregnant women globally and remains the least understood and most challenging maternal morbidity to manage. Although great strides were made in reducing maternal and newborn mortality between 1990 and 2015, this was clearly not enough to achieve the global health goals. To reduce maternal deaths: 1) early detection of PE needs to be improved; 2) effective management of PE/E needs to occur at lower health system levels and should encourage timely care-seeking; and 3) prioritizing the scale up of a comprehensive package of services near to where women live.

Findings: This commentary describes a pragmatic approach to test scalable and sustainable strategies for expanding access to quality under-utilized maternal health commodities, interventions and services. We present a primary health care (PHC) PE/E Model based on implementation research on identified gaps in care in several countries, accepted global best practice and built on the basic premise that PHC providers can take on additional skills with adequate capacity building, coaching and supervision, and community members desire control over their own health. The PHC PE/E model displays the linkages and opportunities to prevent and treat PE/E in a simplified way; however, there are numerous interlinking factors, angles, and critical points to consider including leadership, policies and protocols; relevant medicines and commodities, ongoing capacity building strategies at lower levels and understanding what women and their communities want for safe pregnancies.
\end{abstract}

Conclusion: The PHC model described here uses PE/E as an entry to improve the quality of ANC and by extension the pregnancy continuum. Bringing preventive and treatment services nearer to where pregnant women live makes sense.

\section{Abstract}

* Correspondence: cwarren@popcouncil.org

'Population Council, Washington, DC, USA

Full list of author information is available at the end of the article

(c) The Author(s). 2020 Open Access This article is licensed under a Creative Commons Attribution 4.0 International License, which permits use, sharing, adaptation, distribution and reproduction in any medium or format, as long as you give appropriate credit to the original author(s) and the source, provide a link to the Creative Commons licence, and indicate if changes were made. The images or other third party material in this article are included in the article's Creative Commons licence, unless indicated otherwise in a credit line to the material. If material is not included in the article's Creative Commons licence and your intended use is not permitted by statutory regulation or exceeds the permitted use, you will need to obtain permission directly from the copyright holder. To view a copy of this licence, visit http://creativecommons.org/licenses/by/4.0/. The Creative Commons Public Domain Dedication waiver (http://creativecommons.org/publicdomain/zero/1.0/) applies to the data made available in this article, unless otherwise stated in a credit line to the data. 
(Continued from previous page)

Contexte: Les troubles hypertensifs pendant la grossesse, en particulier la pré-éclampsie et l'éclampsie (PE/E), constituent la deuxième cause de mortalité maternelle dans le monde et est. la moins bien comprise et la plus difficile à gérer. Bien que de grands progrès aient été réalisés dans la réduction de la mortalité maternelle et néonatale entre 1990 et 2015, il est. clair que cela n'a pas suffi pour atteindre les objectifs mondiaux en matière de santé. Pour réduire la mortalité maternelle: 1) la détection précoce de la PE doit être améliorée, 2) la gestion efficace de la PE/E doit se faire à des niveaux inférieurs du système de santé et devrait encourager la recherche de soins en temps utile et 3) la priorité doit être donnée à l'élargissement d'un ensemble complet de services à proximité du lieu de résidence des femmes.

Résultats: Ce commentaire décrit une approche pragmatique visant à tester des stratégies évolutives et durables pour élargir l'accès à des produits, interventions et services de santé maternelle de qualité et sous-utilisés. Nous présentons un modèle PE/E de soins de santé primaires (SSP) basé sur la recherche de mise en œuvre des lacunes identifiées dans les soins dans plusieurs pays, sur les meilleures pratiques mondiales acceptées et sur le principe de base selon lequel les prestataires de SSP peuvent acquérir des compétences supplémentaires avec un renforcement des capacités, un encadrement et une supervision adéquats, et les membres de la communauté souhaitent contrôler leur propre santé. Le modèle PE/E de SSP présente les liens et les possibilités de prévenir et de traiter la PE/E de manière simplifiée. Cependant, il existe de nombreux facteurs, angles et points critiques liés entre eux à prendre en compte, notamment le leadership, les politiques et les protocoles, les médicaments et les produits pertinents, les stratégies de renforcement des capacités en cours aux niveaux inférieurs et la compréhension de ce que les femmes et leurs communautés souhaitent pour des grossesses sans risque.

Conclusion: Le modèle de SSP décrit ici utilise la PE comme entrée pour améliorer la qualité des soins prénataux et par extension le continuum de la grossesse. II est. logique de rapprocher les services de prévention et de traitement du lieu de résidence des femmes enceintes.

\section{Key message}

This model provides a pragmatic approach for improving access to antenatal services for detection, prevention and management of pre-eclampsia and eclampsia at the primary health care level.

\section{Background}

In October 2018, in Astana, Kazakhstan, the global health community reaffirmed their commitment towards universal health coverage and made primary health care (PHC) a cornerstone of their attempt to reach the sustainable development goals (SDGs) by 2030 [1]. Although great strides were made in reducing maternal and newborn mortality between 1990 and 2015 (by 44 and $49 \%$ respectively), this was not enough to achieve the SDGs [2, 3]. More than 830 women and 7700 newborns still die each day from pregnancy-related complications; an additional 7300 women experience a stillbirth with approximately $16 \%$ occurring in pregnancies complicated by hypertension [4]. Of the three direct causes of obstetric mortality (bleeding, sepsis and hypertensive disorders of pregnancy (HDPs) accounting for 27, 11 and 14\% respectively) [5], HDPs, specifically preeclampsia and eclampsia (PE/E), remain the least understood and most challenging to manage [6]. Risks to mothers' cardiovascular and cerebrovascular health decades later and the inter-generational impact of HDPs are only now starting to be understood and remain unquantified in low- and-middle-income countries [6, 7].

Building on the work and successful efforts to prevent and manage postpartum hemorrhage $(\mathrm{PPH})[8,9]$ over the last 10 years - donors and maternal health experts started to focus on other causes of maternal deaths. Globally pre-eclampsia $(\mathrm{PE})$ is the second major killer of pregnant and postnatal women, but unlike $\mathrm{PPH}$, where approximately $70 \%$ can be prevented by administering oxytocin, PE is harder to recognize early and the treatment, magnesium sulphate $\left(\mathrm{MgSO}_{4}\right)$, is only given to those with severe disease. To reduce maternal and perinatal deaths: 1) early detection of $\mathrm{PE}$ needs to be improved; 2) effective management of PE/E needs to occur at lower health system levels and should encourage timely care-seeking; and 3) prioritizing the scale up of a comprehensive package of services near to where women live [10-14].

This commentary describes a pragmatic approach undertaken by a multi-country study (supported by USAID from 2014 to 2019 and implemented by Population Council, through the Ending Eclampsia project) to test scalable and sustainable strategies for expanding access to quality under-utilized maternal health commodities, interventions and services. The project brings an implementation science approach to catalyze focus on $\mathrm{PE} / \mathrm{E}$ by building on evidence-based recommendations 
$[15,16]$. To understand the evolution of the development of the PHC model for PE/E presented here, we need to understand the prevailing practices prior to 2014.

Findings from the multi-country 'MAGPIE trial' in 2001 demonstrated that $\mathrm{MgSO}_{4}$ reduces the risk of eclamptic seizures by half among women with preeclampsia and reduces death from eclampsia [15]. Based on these findings, countries registered $\mathrm{MgSO}_{4}$ on their Essential Medicines List (EML) and introduced it to referral facilities. Although WHO recommends $\mathrm{MgSO}_{4}$ as the anticonvulsant for managing severe $\mathrm{PE} / \mathrm{E}$, (and methyldopa and hydralazine for controlling severe hypertension in pregnancy) $[16,17]$, the burden of calculating dosage of $\mathrm{MgSO} 4$ is daunting, time-consuming and can introduce errors, tempting providers to substitute diazepam for $\mathrm{MgSO}$, a less effective anticonvulsant [8]. Moreover, $\mathrm{MgSO}_{4}$ toxicity may result in respiratory failure and the need for the antidote, calcium gluconate. Even though less than $0.1 \%$ women die due to toxicity, there is a "fear" among providers making them reluctant to use $\mathrm{MgSO}_{4}$ [18]. More recently global advocacy efforts through the UN Commission on Life Saving Medicines for Women and Children 2012-14 focused on procuring quality $\mathrm{MgSO}_{4}$ and only one formulation of $\mathrm{MgSO}_{4}(50 \%$ or $5 \mathrm{~g}$ in $10 \mathrm{ml})$ to reduce the calculation challenges that exist [8].

Following the more widespread uptake of $\mathrm{MgSO}_{4}$ in referral facilities, a few studies also demonstrated the feasibility and acceptability of task-sharing management of PE to lower levels where providers administer a loading dose of $\mathrm{MgSO}_{4}$ correctly and refer the patient for further management $[6,19,20]$. However, WHO recommendations on task shifting or sharing maternal and newborn health $(\mathrm{MNH})$ services do not include use of antihypertensives for severe hypertension for lower level cadres to prescribe [21]. Many countries are guided by WHO and therefore do not allow these cadres to prescribe and administer life-saving drugs for pregnant women with obstetric complications, yet this is where women often first seek care. Although 29/31 countries surveyed had $\mathrm{MgSO}_{4}$ on their EML in 2011, there is limited information available on specific antihypertensives for use during pregnancy in these countries [17].

\section{Landscape analysis in five countries - baseline findings}

In 2015-2016, we conducted landscape analyses in Bangladesh [10], Nigeria [11], and Pakistan [12] on access to PE/E services. Further in-depth assessments in Ethiopia and Kenya provided a broader picture of the provision and experience of care for PE/E across sub Saharan Africa and south east Asia. Key findings included providers' poor knowledge and skills in addition to a lack of essential commodities and equipment. Facilities were more likely to have oxytocin for prevention and management of PPH than $\mathrm{MgSO}_{4}$ to manage PE/E. Specific gaps at the lower facility levels include lack of task shifting policy, weak referral policies, lack of access and use of antihypertensives; lack of postpartum monitoring; and lack of community awareness around PE/E including danger signs. Headaches and blurred vision associated with $\mathrm{PE} / \mathrm{E}$ are perceived as malaria or 'overthinking' and swollen ankles are perceived as normal. Women who experienced PE/E describe multiple contacts with the health system before receiving the necessary lifesaving care [10-12]. The learning from the country level landscape analyses, in collaboration with input from key stakeholders - including in-country Ministry of Health officials, partners working in $\mathrm{MNH}$ and discussions with members of national and international technical working groups - formed the basis of a comprehensive PHC model for PE/E, tested through implementation research between 2016 and 2018. The model also built on evidence-based recommendations from WHO and other international experts $[15,20,22]$.

\section{The primary health care - pre-eclampsia/eclampsia model}

We present a PHC PE/E Model (see Fig. 1) based on implementation research on identified gaps in care in several countries, accepted global best practice and built on the basic premise that PHC providers can take on additional skills with adequate capacity building, coaching and supervision, and community members desire control over their own health [1]. By using PE as a lens, we believe this model is transferrable across countries and practices along the pregnancy continuum with a particular focus on antenatal care (ANC). However, our research has also shown that without appropriate policies, sufficient finances, supplies/medicines in place and effective governance/ leadership, the success of the model may be limited [10-12]. Here, we describe the PHC model for PE/E care representing a set of critical interventions for early detection and quality $\mathrm{PE} / \mathrm{E}$ prevention and management tested through IR:

\section{Community level}

- Use women's groups as a platform to increase awareness on danger signs and importance of early care seeking during pregnancy (Cross River state, Nigeria).

- Include country-specific community-based cadres: Community Midwives (CMWs) in Sindh Province, Pakistan, identified as capable providers of $\mathrm{MgSO}_{4}$ loading dose with referral. 


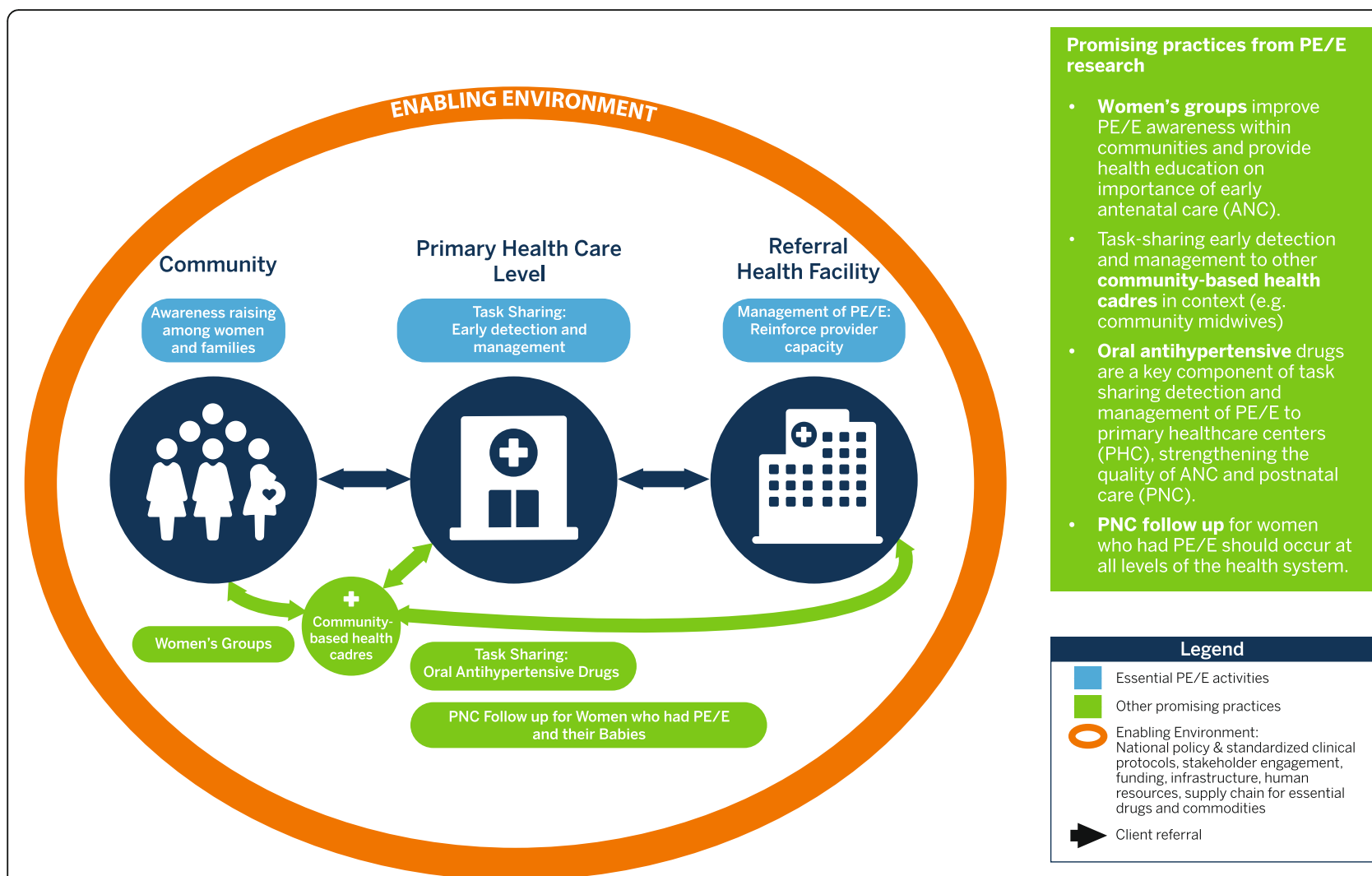

Fig. 1 Primary Health Care - Preeclampsia /Eclampsia Model

\section{Primary health care}

- Use PE/E as a lens on quality of ANC:

Encourage early care seeking behavior for enabling early detection of high blood pressure (BP).

Raise awareness of signs and symptoms and what women should expect/ask at facilities during ANC and postnatal (PNC) contacts.

- Build capacity / improve performance of service providers:

Mobilize master trainers who are available locally.

Develop training plans, which include followup mentoring, coaching and supportive supervision, including refresher training as necessary during facility visits.

Ensure competent and confident providers can identify, monitor, stabilize and refer patients to higher levels.

- Ensure functionality and/or readiness of system:

Availability and use of equipment, and supplies for detection and treatment: BP machines, stethoscope, urine dipsticks, patella hammer, syringes, needles, etc.
Ensure consistent supply of quality medicines for managing HDPs; antihypertensives (those readily available in country - labetalol, nifedipine, or alpha methyldopa), $\mathrm{MgSO}_{4}$, and calcium gluconate.

Engage pharmacy workers and logistics officers to ensure they understand the importance of consistent stock of equipment and commodities for obstetric complications.

- Provide quality care:

Inform women and families routinely on danger signs/symptoms of pregnancy. This could be done through individual visits or through group counseling.

Check BP and urine albumin routinely to detect PE early $[15,22]$

If high $\mathrm{BP}$ or PE is identified, monitor closely, provide antihypertensives as appropriate.

If $\mathrm{BP}$ is not controlled or severe $\mathrm{PE} / \mathrm{E}$ ensues, stabilize with antihypertensive, loading dose of $\mathrm{MgSO}_{4}$ and refer to appropriate facility $[16,22,23]$.

- Ensure hypertension is controlled:

Use of a simple algorithm/clinical protocol: monitor BP closely. 
Prescribe anti-hypertensive for moderate to severe hypertension [24].

Ensure referral system is in place:

Assist or identify locally available transport.

Referral notification with higher level facility.

Ensure post-referral monitoring/follow-up.

\section{Referral health facility}

- Functional referral facility (Emergency Obstetric and Neonatal Care):

Ensure maternity units have received training on identification and management of PE/E.

Ensure use of nationally/internationally recognized treatment algorithms/protocols.

Ensure necessary equipment, and commodities, in place.

Ensure expertise and appropriate skills mix of staff available.

- Skilled providers to manage PE/E:

Ensure providers are confident and capable to manage PE/E appropriately (as above).

Assist local staff to create a functioning referral and counter referral plan.

- Monitor women with PE/E closely post-delivery and postpartum:

Ensure they are not discharged during the first $48 \mathrm{~h}$ or until BP is stabilized.

Ensure monitoring and postnatal follow-up care of women who experienced PE/E.

Systematize identification of health outcomes for mothers and offspring in the extended postnatal period and later in life -including women's awareness of increased risk of noncommunicable diseases such as chronic hypertension, cardiovascular and cerebrovascular disease.

The model can be adapted to different country contexts or tailored to country level. Here are the gaps to consider.

\section{Critical issues to consider}

The Primary Health Care Pre-eclampsia/ eclampsia (PHC PE/E) model (Fig. 1) displays the linkages and opportunities to prevent and treat PE/E in a simplified way; however, there are numerous interlinking factors, angles, and critical points to consider. The different elements of the model each play an important role and have different resource implications, when ensuring that women with $\mathrm{PE} /$ $\mathrm{E}$ are treated quickly and appropriately. Policies must be in place that include task sharing/shifting to $\mathrm{PHC}$ providers to prescribe antihypertensive drugs for managing moderate to severe hypertension (systolic $\mathrm{BP} \geq 160$ or diastolic $\geq \mathrm{BP}-110$ ) and administer the $\mathrm{MgSO}_{4}$ loading dose to women with severe PE/E. Standardized protocols need to be used all the time by everyone to ensure consistent management across the system [16, 22]. Leadership at facility, district, regional, national levels is critical to champion the implementation of the policy.

The medicines $\left(\mathrm{MgSO}_{4}\right.$, calcium gluconate and antihypertensive drugs) recommended by WHO must be available where needed. Support to the public sector supply chain is required in order to have the right medicine, in the right place, at all times - and availability in the private sector or alternatives for when either system fails. Health care providers at PHC level must have the necessary equipment and logistics and the knowledge and skills to identify, provide initial treatment (loading dose of $\mathrm{MgSO}_{4}$ and antihypertensive) and refer [14, 24]. At referral facilities, providers should have the expertise and capacity for optimal emergency management of PE/ E. Providers should benefit from refresher training, emergency drills/updates as needed, ongoing supportive supervision, and mentoring. However, it is important to recognize that task shifting or sharing to lower cadres only makes sense if those cadres already have basic clinical skills (for example taking BP, administering injections) [22, 23]. Evidence shows that $\mathrm{MgSO}_{4}$ should not be 'pushed' to the lowest level in communities (i.e. community health workers) but stay within a clinical setting [25]. We cannot forget that the women and communities must be involved, they must be knowledgeable and able to advocate for themselves and to ensure providers are listening to them. It is important that they recognize the danger signs, attend ANC in the first trimester and have at least eight contacts to be screened for signs of $\mathrm{PE}$ in order to minimize the impact of this disease on themselves and their newborns. Community platforms such as women's groups - can be leveraged to raise awareness about health topics, including PE/E [26, 27]. Referral pathways must be well defined to achieve the best outcomes. During training, cadres (from consultants to lower level providers) at all levels require updating in the referral process to ensure women receive prompt care. Close monitoring of women during labor and delivery is critical as is monitoring during the immediate postpartum period when $20-30 \%$ of hypertensive and eclamptic seizures occur and again before she leaves the facility, followed by comprehensive follow-up PNC. This PHC model complements the International Society for the Study of Hypertension in Pregnancy (ISSHP) recommendations for low resource settings [24] and resonates with new guidelines in South Africa [28].

This project has been pushing the agenda forward to provide better care for women on HDPs and PE/E and has an expanded view of what is needed [26, 27, 29, 30]. Ensuring services are available at lower levels providers opportunities to identify pre-eclampsia early, timely 
delivery and effective treatment for those with a severe form of the condition [14]. The results of the implementation research linked to this PHC model will be published as separate manuscripts. We are also considering reviewing the cost-effectiveness. If the mission of a public health system is to protect and improve pregnant women and their babies' healthcare, it will be imperative for Ministries of Health to act comprehensively in addressing the issues of $\mathrm{PE} / \mathrm{E}$ and $\mathrm{MNH}$ more broadly and specifically at PHC level $[15,18,24,30]$.

\section{Conclusion}

The PHC model described here uses PE/E as an entry to improve the quality of ANC and by extension the pregnancy continuum. Bringing preventive and treatment services nearer to where pregnant women live makes sense. The global community have recognized this by reendorsing PHC through the 2018 Astana commitment. Implementation research suggests that this $\mathrm{PHC}-\mathrm{PE} / \mathrm{E}$ model works and can improve the current and future health of women and infants.

\section{Abbreviations}

ANC: antenatal care; BP: blood pressure; CMWs: community midwives; HDP: hypertensive disorders of pregnancy; $\mathrm{MgSO}_{4}$ : magnesium sulphate; PE/ E: preeclampsia and eclampsia; PHC: primary health care; PNC: postnatal care; PPH: postpartum hemorrhage; SDG: Sustainable Development Goal

\section{Acknowledgements}

We wish to acknowledge the contribution of Ending Eclampsia colleagues and to Mary Ellen Stanton and Michelle Hindin for their input and review of an earlier version.

\section{Authors' contributions}

CEW conceived the idea and wrote the first draft, all authors critically reviewed the manuscript, read and approved the final version of the manuscript.

\section{Funding}

This work was supported by the US Agency for International Development (USAID), under the terms of cooperative agreement number [USAID APSOAA-14-000048]. This article reflects the views of the authors and does not represent the views of the U.S. Government.

\section{Availability of data and materials}

Not applicable.

Ethics approval and consent to participate

Not applicable.

\section{Consent for publication}

Not applicable.

\section{Competing interests}

The authors declare that they have no competing interests.

\section{Author details}

'Population Council, Washington, DC, USA. ²Population Council, Dhaka, Bangladesh. ${ }^{3}$ Julius Centre for Health Sciences and Primary Care, UMC, Utrecht, The Netherlands. ${ }^{4}$ USAID, Washington DC, USA.
Received: 27 August 2019 Accepted: 11 March 2020

Published online: 06 April 2020

\section{References}

1. Declaration of Astana. Astana: global conference on primary health care. Geneva: WHO; 2018. Available at https://www.who.int/primary-health/ conference-phc. Accessed 20 Feb 2019.

2. World Health Organization, UNICEF, UNFPA, the World Bank, United Nations Population Division. Trends in maternal mortality: 1990-2013. Geneva: Switzerland WHO; 2014. Available at. http://apps.who.int/iris/ bitstream/10665/112682/2/9789241507226_eng.pdf Accessed 28 Dec 2018.

3. United Nations Inter-Agency Group for Child Mortality Estimation (UN IGME). Levels \& trends in child mortality: report. New York: United Nations; 2018. Available at https://www.un.org/en/development/desa/population/ publications/mortality/child-mortality-report-2018.asp Accessed 20 Apr 2019.

4. Lawn JE, Blencowe $H$, Waiswa P, et al. Stillbirths: rates, risk factors, and acceleration towards 2030. Lancet. 2016;387(10018):587-603.

5. Say L, Chou D, Gemmill A, Tunçalp Ö, Moller AB, Daniels JD, et al. Global causes of maternal death: a WHO systematic analysis. Lancet Glob Health. 2014;2(6):323-33.

6. Salam RA, Das JK, Ali A, Bhaumik S, Lassi ZS. Diagnosis \& management of preeclampsia in community settings in low and middle-income countries. J Family Med Prim Care. 2015;4(4):501-6.

7. von Dadelszen P, Firoz T, Donnay F, et al. Preeclampsia in low- and middleincome countries-health services lessons learned from the PRE-EMPT (PREEclampsia-Eclampsia Monitoring, Prevention and Treatment) project. J Obstet Gynaecol Can. 2012;34(10):917-26.

8. Pronyk PM, Nemser B, Maliqi B, for the UNCoLSC Technical Resource Teams, UN Agency Leads, and UNCoLSC Monitoring and Evaluation Advisory Group, et al. The UN Commission on Life Saving Commodities 3 years on: global progress update and results of a multi-country assessment. Lancet Glob Health. 2016:4:276-86.

9. Prata N, Bell S, Weidert K. Prevention of postpartum hemorrhage in lowresource settings: current perspectives. Int J Women's Health. 2013;5:737-52. https://doi.org/10.2147/IJWH.S51661.

10. Warren CE, Hossain SM, et al. Landscape analysis of pre-eclampsia/eclampsia in Bangladesh report. New York: Population Council; 2016. Available at http://www.endingeclampsia.org/wp-content/uploads/2017/04/FINALLandcapeAnalysis-Bangladesh-USAID-GA31-EndingEclampsia-Mar2016.pdf Accessed 30 Nov 2018.

11. Warren CE, Ishaku SM et al, Landscape analysis of pre-eclampsia/eclampsia in Nigeria report. New York: Population Council; 2016. Available at. http:// www.endingeclampsia.org/wp-content/uploads/2017/04/EndingEclampsiaLandscapeReport-Nigeria.pdf Accessed 30 Nov 2018.

12. Mir AM, Shaikh $\mathrm{S}$, et al. Landscape report on pre-eclampsia/eclampsia in Pakistan report. New York: Population Council; 2016. Available at https:// www.popcouncil.org/uploads/pdfs/2016RH_LandscapingAnalysisPakistan. pdf. Accessed 2 Feb 2020.

13. World Health Organization (WHO). Recommendations on antenatal care for a positive pregnancy experience. Geneva: WHO; 2016. Available at https:// www.who.int/reproductivehealth/publications/maternal_perinatal_health/ anc-positive-pregnancy-experience/en/. Accessed 29 Dec 2018.

14. Hodgins S. Pre-eclampsia as underlying cause for perinatal deaths: time for action. Glob Health Sci Pract. 2015;3(4):525-7. https://doi.org/10.9745/GHSPD-15-00350 Published 2015 Dec 17.

15. Magpie Trial Collaborative Group. Do women with pre-eclampsia, and their babies, benefit from magnesium sulphate? The Magpie Trial: a randomized placebo-controlled trial. Lancet. 2002;359(9321):1877-90.

16. World Health Organization (WHO). Recommendations for prevention and treatment of pre-eclampsia and eclampsia. Geneva: WHO; 2011. Available at: https://apps.who.int/iris/bitstream/handle/10665/44703/9789241548335_ eng.pdf. Accessed 29 Dec 2018.

17. World Health Organization (WHO). Model list essential medicines 18th list. Geneva: WHO; 2013. Available at https://www.who.int/medicines/ publications/essentialmedicines/en. Accessed 29 Nov 2018.

18. Smith JM, Lowe RF, Fullerton J, et al. An integrative review of the side effects related to the use of magnesium sulfate for preeclampsia and eclampsia management. BMC Pregnancy Childbirth. 2013;13:34 Available at. http://www.biomedcentral.com/1471-2393/13/34. 
19. Firoz Sanghvi H, Merialdi M, von Dadelszen P. Pre-eclampsia in low- and middle-income countries. Best Pract Res Clin Obstet Gynaecol. 2011;25:53748.

20. Shamsuddin L, Nahar K, Nasrin B, Nahar S, et al. Use of parenteral magnesium sulphate in eclampsia and severe pre-eclampsia cases in a rural set up of Bangladesh. Bangladesh Med Res Counc Bull. 2005;31(2):75-82.

21. World Health Organization (WHO). Recommendations: optimizing health worker roles to improve access to key maternal and newborn health interventions through task shifting. Geneva: WHO; 2012. Available at https:// apps.who.int/iris/bitstream/handle/10665/250796/9789241549912-eng. pdf?sequence=1. Accessed 30 Nov 2018.

22. Brown M, Magee LA, Kenny LC, on behalf of the International Society for the Study of Hypertension in Pregnancy (ISSHP), et al. Hypertensive disorders of pregnancy: ISSHP classification, diagnosis, and management recommendations for international practice. Hypertension. 2018:72:24-43.

23. Salam RA, Qureshi RN, Sheikh $\mathrm{S}$, et al. Potential for task-sharing to Lady Health Workers for identification and emergency management of preeclampsia at community level in Pakistan. Reprod Health. 2016;13(Suppl 2): 107. Published 2016 Sep 30. https://doi.org/10.1186/s12978-016-0214-0.

24. Fujioka A, and Smith J. Prevention and management of postpartum hemorrhage and pre-eclampsia/eclampsia: national programs in selected USAID program-supported countries: Maternal and Child Health Integrated Program (MCHIP) global status reports. 2011. Available at: http://resources. jhpiego.org/resources/prevention-and-management-postpartumhemorrhage-and-pre-eclampsiaeclampsia-national Accessed Dec 202019.

25. Obstetrical and Gynecological Society of Bangladesh (OGSB), et al. Operationalizing the proposed national protocol for the prevention and management of severe pre-eclampsia and eclampsia patients using loading dose of magnesium sulphate at community level in Bangladesh. New York: Population Council. 2014. Available at https://www.popcouncil.org/research/ results?keywords=magnesium+sulphate\&resources=yes\&projects Accessed Feb 2020.

26. Pooja S, Nwala E, McClair T, Ishaku S, Warren CE. Engaging community women's groups to improve maternal health care delivery in cross river, Nigeria: implementation research report. New York: Population Council; 2019. Available at https://www.popcouncil.org/uploads/pdfs/2019RH_EECommunityWomensGroupsCRS.pdf. Accessed 20 Jan 2020.

27. Ali M, et al. Expanding services to detect, manage, and prevent preeclampsia and eclampsia in Tando Allahyar District of Sindh Province, Pakistan implementation research report. New York: Population Council; 2019. Available at https://www.popcouncil.org/uploads/pdfs/2019RH_EEExpandingServicesPakistan.pdf. Accessed 20 Jan 2020.

28. Moodley J, et al. Hypertensive disorders in pregnancy: 2019 national guideline. S Afr Med J. 109:9 ISSN 2078-5135. Available at: http://www.samj. org.za/index.php/samj/article/view/12723. Accessed 20 Jan 2020.

29. Nwala E, Anaba U, Sripad P, Ishaku SM, Warren CE. Feasibility and acceptability of community health extension workers to identify and treat hypertension associated with pregnancy, implementation research report. New York: Population Council; 2019. Available at https://www.popcouncil. org/uploads/pdfs/2019RH_EE-CHEWsAntiHypertensives.pdf. Accessed 15 Jan 2020.

30. Hossain S, Roy S, Sultana K, Warren CE. Assessing the effect of a primary health care intervention for improving pre-eclampsia and eclampsia knowledge and practice in Bangladesh. New York: Population Council; 2019. Available at http://www.endingeclampsia.org/wp-content/uploads/2019/10/ Report-Bangladesh-USAID-Ending-Eclampsia-Final-Study-Report_2019.pdf Accessed 21 Jan 2020.

\section{Publisher's Note}

Springer Nature remains neutral with regard to jurisdictional claims in published maps and institutional affiliations.

Ready to submit your research? Choose BMC and benefit from:

- fast, convenient online submission

- thorough peer review by experienced researchers in your field

- rapid publication on acceptance

- support for research data, including large and complex data types

- gold Open Access which fosters wider collaboration and increased citations

- maximum visibility for your research: over $100 \mathrm{M}$ website views per year

At BMC, research is always in progress.

Learn more biomedcentral.com/submissions 